\title{
Research on Operating Performance and E-business Marketing Strategy in Retail Enterprises based on Online Shopping
}

\author{
Yongqiang Zhang, Yanlei Gao, Xiang Li and Duchun Wang* \\ College of Economics and Management, \\ Northeast Agricultural University, Harbin, China \\ *Corresponding author: \{duchun wang\} (zyqlss@126.com)
}

\begin{abstract}
In recent years, with the rapid development of internet technology, enterprise business model has entered a new century. The emergence of network economy has forced retail enterprises to change the original marketing mode, global information resources can be shared instantly, which greatly improve the operational efficiency and reduce the cost. In this paper, we analyze the influence factors that impact on retail enterprises based on consumers online shopping behavior, survey data from small and medium enterprises. The result shows that macro environment factors, market competition, enterprise self factors will affect the enterprise's e-commerce performance, and significantly promote the enterprise's market strategy innovation. Therefore, it is an important way to improve the competitiveness of enterprises by carrying out the E-business market strategy.
\end{abstract}

Keywords: Marketing strategy; Retail enterprises; online shopping; E-business innovation

\section{Introduction}

In recent years, with the rapid development of internet technology, enterprise business model has entered a new century. Many traditional enterprises have adopted Internet technology in the online publicity, sales of its products, and have achieved great success, the huge gains; human society began to enter the era of network economy. The emergence of network economy has forced retail enterprises to change the original marketing mode, global information resources can be shared instantly, and no longer subject to time or geographical conditions, which greatly improve the operational efficiency of production and business, and to make management and business process of the cost greatly reduced, therefore, in the retail business will naturally lead to a marketing model change [1]. Marketing is an important means to improve the competitiveness of retail enterprises. But because Chinese retail enterprises are developing in the traditional planned economy, the marketing idea of the enterprise is relatively backward, the marketing means is single, the innovation consciousness is not strong, the marketing method of many retail enterprises is the price, discount and so on. The same price war caused the vicious competition in China's retail industry, which led to the overall decline in the retail industry, which is not conducive to the overall competitiveness of China's retail enterprises. At the same time, China's retail enterprises still exist in the target market positioning, customer loyalty is not high, and the various aspects (government, suppliers, etc.) are not smooth and other issues [2]. These problems are the inevitable result of the traditional marketing over time, and it will be more and more important in the development of China's retail enterprises and the important factor to improve the competitive advantage.

* Duchun Wang is the corresponding author. 
The sustained and rapid development of information technology has made the retail enterprises into a global competition. The marketing mode of enterprises is changing, e-commerce is one of the typical representative modes, which has become an important platform for enterprises to survive and develop, and promote the transformation of the traditional marketing mode to the electronic business environment. This paper analyzes the factors that influence the change of marketing mode in e-commerce environment, and gives a comprehensive analysis of the mechanism of the role of e-commerce in the marketing mode of retail enterprises, and analyzes the properties, types, characteristics and advantages of the new marketing mode, which makes the new marketing model more clear in theory. This paper analyzes the influence of e-commerce environment on the marketing mode of retail enterprise, and constructs the theoretical model of this paper, and puts forward the research hypothesis.

\section{Literature Review}

Marketing as a practical management discipline, with the development of the economy and constantly changing. On the marketing model, in the past due to the limitations of the conditions, the customer as the center of the marketing model is difficult to achieve real. However, along with the arrival of the Internet era, an Internet based network virtual market began to form and gradually grow and grow.

\subsection{Electronic Commerce Model}

From the perspective of communication, electronic commerce is the transmission of information, products, services or payment through telephone lines, computer networks, or other electronic means. From the perspective of business processes, ecommerce is a tool to help manufacturers, consumers and management reduce service costs, while improving the quality of goods and services. From the perspective of online e-commerce provides the ability to buy and sell products and information through Internet and other online services. Under the background of $4 \mathrm{C}$, the marketing mode of e-commerce environment is the dialogue between customers and enterprises. The enterprise can make the most of the profit of the enterprise after a clear understanding of the needs of each customer. So, the relationship between the enterprise and the customer is one to one relationship marketing, is inseparable from unbreakable, network immediate interaction, beyond time and space and other characteristics is a strong technical support for this model. The involvement of electronic commerce, which makes the evolution of the traditional market, need to establish a more effective way from the higher level in order to establish a new type of relationship between the enterprise and the customer [3]. 4Rs theory arises at the historic moment: reaction and repay; the biggest characteristic of the marketing theory is the competition of the new frame. 4Rs according to the market and the increasingly fierce competition in the situation, focus on business and customer interaction and win-win, not only to meet the needs of customers, and actively create demand, the use of optimization and system thinking to integrate marketing, through the relationship, relationship, reaction and other forms of unique relationship with customers, the business and customers together to form a competitive advantage. It can be said that $4 \mathrm{Rs}$ is the new century marketing theory of innovation and development, will have a positive and important impact on marketing practices.

Electronic commerce has made great changes in the structure of the original market and business environment. For enterprises, e-commerce is not only a new technology, but also a new way of management and business philosophy [4]. The arrival of the era of $\mathrm{E}$-commerce requires the improvement of the function of the commodity trading, from the circulation of a company and the whole social 
marketing process to reduce the cost and meet customer needs. Under the environment of e-commerce marketing model better meets the increasingly fierce competition in the market for personalized customer needs, from the means solve the difficult to solve in the past to quickly understand and meet customer needs, as well as the enterprise and the market for a good docking, and the basic defect of modern management and marketing theory is corrected, the enrichment and development of modern marketing theory.

\subsection{Marketing Strategy}

The definition of marketing, different scholars have different understanding. Marketing Kotler Philip is defined as marketing is a social and managerial process for individuals or groups by creating, offering, and exchanging products and value with others in order to obtain the desired object [5]. Under the American Marketing Association, marketing is an organized activity, which includes creating "value", communicating value to the customer, and maintaining the relationship between the management company and the customer. These two kinds of representative meanings are defined; the core of marketing is the exchange, which is the process of exchanging the two parties to meet each other.

The marketing mode is the concrete marketing activity in the enterprise marketing activity form or the marketing activity process, mainly including the marketing idea, the marketing organization and the marketing technology these three essential factors. Marketing concept refers to the enterprise in the process of marketing activities, in dealing with enterprise, customer and social three aspects of the attitude, ideas and concepts, marketing organization refers to the organization relationship between manufacturers and distributors, marketing means is the method used in the marketing process, also including advertising promotion and other activities. The marketing organization and the marketing method often depends on the marketing idea, the marketing idea plays the guiding role. These three elements are mutual influence and complement each other, as a "model", it is an organic whole, cannot be a simple way to change the organization of the market or the way of marketing to replace the entire marketing model. For a certain kind of marketing mode, marketing organization and marketing technology is often determined by the marketing concept, so it is better to determine the marketing model is better, the key is to provide users with what kind of marketing services, rather than simply selling products.In the 20th century, Deniss (2014) defines the difference between controllable and uncontrollable factors, the earliest proposed marketing mix theory [6]. The product life cycle, the market segmentation concept proposed by the product life cycle and the market segmentation has provided the beneficial theory and method support for the marketing activities. In the brand image and marketing audit ideas, the enterprises can more rational development of marketing strategy and strategy. Shoki (2012) believes that all departments within the enterprise should be able to form a marketing oriented according to customer orientation, which requires the management of enterprises should be marketing [7]. Zaridis (2014) clearly put forward the concept of global marketing [8]; the Multi-National Corporation should provide the world with a relatively uniform product and communication means. Manjit (2013) proposed relationship marketing, and from the perspective of service industry to define: relationship marketing is to attract, maintain and improve customer relationship in various service organizations [9]. Grant (2014) put forward the broadest definition, they think that relationship marketing is to establish, develop and maintain a successful relationship between the exchanges of all marketing activities [10]. 


\section{Model Design and Research Hypothesis}

\subsection{Factors that Affecting the Marketing Model}

E-commerce not only changed the enterprise marketing mode, but also promotes the enterprise to the management idea, the decision way, the business process combination, the marketing mode of strategic thinking and change. There are many factors that influence the change of marketing mode of retail enterprises. These factors can be positive or negative. In this paper, these factors are divided into three categories, namely, macro environmental factors, market competition factors, enterprise self factors. The following three aspects of the factors were analyzed.

\section{Model Design and Research Hypothesis}

\subsection{Factors that Affecting the Marketing Model}

E-commerce not only changed the enterprise marketing mode, but also promotes the enterprise to the management idea, the decision way, the business process combination, the marketing mode of strategic thinking and change. There are many factors that influence the change of marketing mode of retail enterprises. These factors can be positive or negative. In this paper, these factors are divided into three categories, namely, macro environmental factors, market competition factors, enterprise self factors. The following three aspects of the factors were analyzed.

1) Macro environmental factors: policy factors are to admit of no doubt the economic and social influence. The business activities of the enterprise are the part of the social economic life, and the social economic life is always influenced by the political life. Therefore, in the current social and economic environment, policy formulation, improvement and implementation, for the retail enterprises in the direction of e-commerce marketing model change plays a guiding role. The ability to develop a healthy and stable business depends on the construction of electronic commerce. The Chinese government attaches great importance to the legislation of electronic commerce; the government departments concerned are studying, modifying and making relevant laws and regulations. The credit system has been established in the computer information network security. Credit mechanism is an important cornerstone for the survival and development of the market economy. Credit system is the premise and basis of electronic commerce, there is no guarantee that any electronic commerce cannot be realized.

2) Market competition factors: retail enterprises in the information sharing, reduce the processing time, save labor costs, and improve the efficiency of enterprises in the presence of huge demand for electronic commerce. Ecommerce can provide new opportunities and space for the survival of retail enterprises. The enterprise can reduce the cost of sales and reduce operating expenses, improve management efficiency, speed up the assets turnover rate. The enterprise uses the specific strategy to meet the needs of consumers. Electronic commerce marketing model has no time and space constraints, it runs 24 hours a day, the tentacles extend to every place in the world. Therefore, the use of the Internet to do business can be reached in the past rely on people to sell or rely on advertising sales cannot meet the market. In addition to the use of e-commerce can also improve the efficiency of the staff, enhance communication with partners, supply sources more stable, expand market share, and improve profit margins. 
3) Enterprise's own factors: the influence of the retail enterprise marketing mode of the transformation of its own factors, the strength factor, the strength factor, the management factor, the commodity factor. Talent factor in e-commerce model has important influence, according to the 2013 SME e-commerce application survey results show that in the small and medium enterprise electronic commerce application of its own factors, the "professional" lack of the proportion of the company is generally considered to be a large company has the ability to provide them with the service and support; large companies are willing to invest in their reputation and brand, so the size of the company is often able to increase consumer confidence.

\subsection{Research Hypothesis}

Macro environment means the social and economic environment under the leadership of the government. In the process of e-commerce development, the government should give positive support to the policy, which shows that the government attaches great importance to electronic commerce, actively making laws and regulations, and ensuring the healthy and orderly development of e-commerce in the law. These have laid an important foundation for the establishment and development of electronic commerce. So we put forward the first hypothesis of this article:

H1: when macro environment is better, the more likely the retail enterprise marketing model change.

For more loyal customers, and the business of the company's profit level determines whether it continues to stay in the industry. It can be seen that these factors in the market competition environment have a strong impact on the retail business decision-making and marketing model, so we put forward the following assumptions:

H2: the more intense market competition, the more likely the retail enterprise marketing model change.

The human factor in the enterprise has the important influence to the electronic commerce pattern, they are not only the decision maker, but also the decision maker; the enterprise own economic strength, the brand strength and so on to decide whether or not to have the ability to carry on such a marketing pattern transformation. So we put forward the following hypothesis:

H3: when the enterprises own strength, the more likely that the retail enterprises will change the marketing model.

\section{Empirical Analysis}

\subsection{Variable Description}

As mentioned above, the system error B is effectively controlled, and the reliability and validity of the system can be used to test the reliability and validity of the system. According to the previous analysis of the factors affecting the marketing mode of retail enterprises under the electronic commerce environment, the design scale is shown in Table 1. 
Table 1. Variable Description

\begin{tabular}{|c|c|c|}
\hline Index & Structure variable & Observation variable \\
\hline \multirow{12}{*}{$\begin{array}{l}\text { Enterprise Marketing } \\
\text { Mode Innovation }\end{array}$} & \multirow{4}{*}{ Macro Environnent Factors } & Policy factor \\
\hline & & Legal factors \\
\hline & & Economic factor \\
\hline & & Social and cultural factors \\
\hline & \multirow{4}{*}{ Market Competition Factor } & Demand factor \\
\hline & & Price factor \\
\hline & & Competitive factors \\
\hline & & Benefit factor \\
\hline & \multirow{4}{*}{ Enterprise Self Factor } & Talent factor \\
\hline & & Strength factor \\
\hline & & Management factor \\
\hline & & Commodity factor \\
\hline
\end{tabular}

\subsection{Sample Statistics}

The object of the survey is the retail business of Harbin City, the unit is a single retail enterprises. According to the scale of retail enterprises, the number of employees is less than 100 enterprises for small retail enterprises; the number of employees is 500 people of enterprises for medium-sized retail enterprises, the number of employees more than 500 enterprises for large retail enterprises. Therefore, this investigation of the enterprise, both market such a global chain of large retail enterprises, there is only a single store to operate a single variety of small retail business. Data were collected using a questionnaire survey, access member is except himself, also mobilized all relatives and friends of the relationship between, through personal interviews and online mail distribution in a variety of ways to obtain raw data with related enterprises, in 2014 in late March of retail business of Harbin City in the survey, questionnaires were distributed to a total of 11, after screening the 1000 valid questionnaires. Through descriptive statistical analysis of the data, the characteristics of the sample are divided into three characteristics: the nature of the enterprise, the size of retail enterprises, and the position of the respondents in the enterprise, as shown in Table 2.

\section{Table 2. Sample Characteristics}

\begin{tabular}{|c|c|c|c|c|c|}
\hline $\begin{array}{c}\text { Enterprise } \\
\text { property }\end{array}$ & $\%$ of total N & $\begin{array}{c}\text { Enterprise } \\
\text { scale }\end{array}$ & $\%$ of total N & Position & $\%$ of total N \\
\hline $\begin{array}{c}\text { Chinese } \\
\text { funded }\end{array}$ & $60.00 \%$ & $\begin{array}{c}\text { Small } \\
\text { business }\end{array}$ & $31.00 \%$ & $\begin{array}{c}\text { Senior } \\
\text { Manager }\end{array}$ & $7.00 \%$ \\
\hline Joint venture & $27.00 \%$ & $\begin{array}{c}\text { Medium- } \\
\text { sized }\end{array}$ & $61.00 \%$ & $\begin{array}{c}\text { Marketing } \\
\text { Manager }\end{array}$ & $72.00 \%$ \\
\hline $\begin{array}{c}\text { Foreign } \\
\text { enterprise }\end{array}$ & $13.00 \%$ & $\begin{array}{c}\text { Large } \\
\text { enterprises }\end{array}$ & $8.00 \%$ & Employee & $21.00 \%$ \\
\hline Total & $100 \%$ & Total & $100 \%$ & Total & $100 \%$ \\
\hline
\end{tabular}

\subsection{Reliability and Validity Analysis}

In order to confirm the quality of the scale, the reliability analysis of the factors affecting the electronic commerce marketing model transformation is carried out. Reliability analysis, we use the measurement standard is Cronbach's $\alpha$. When its value is between 0 to 1 , it shows that the higher the reliability. Generally coefficient is greater than 0.7 as good. Through data analysis, the results of Table 3 are obtained. The coefficient is 
0.702 , which indicates that the scale has good reliability. And then we make factor analysis of the impact of the electronic commerce marketing mode change, such as Table 4 and Table 5.

Table 3. Reliability Analysis

\begin{tabular}{|c|c|}
\hline Cronbach's Alpha & N of Items \\
\hline .702 & 13 \\
\hline
\end{tabular}

Table 4. KMO and Bartlett test

\begin{tabular}{|l|c|c|}
\hline \multicolumn{2}{|c|}{ Kaiser-Meyer-Olkin } & 0.721 \\
\hline \multirow{3}{*}{ Bartlett test } & Approximate chi-square & 378.769 \\
\cline { 2 - 3 } & df & 78 \\
\cline { 2 - 3 } & Sig. & 0.000 \\
\hline
\end{tabular}

Table 5. Factor Analysis

\begin{tabular}{|c|c|c|c|}
\hline \multirow{2}{*}{ Factors } & \multicolumn{3}{|c|}{ Component } \\
\cline { 2 - 4 } & 1 & 2 & 3 \\
\hline Policy factor & .530 & & \\
\hline Legal factors & .578 & & \\
\hline Economic factor & .632 & & \\
\hline Social factors & .658 & & \\
\hline Demand factor & & .537 & \\
\hline Price factor & & .528 & .708 \\
\hline Competitive factors & & .666 & .622 \\
\hline Benefit factor & & & .727 \\
\hline Talent factor & & & .565 \\
\hline Strength factor & & & \\
\hline Management factor & & & \\
\hline Commodity factor & & & \\
\hline
\end{tabular}

\subsection{Regression Analysis}

Through regression analysis, the significant test of regression variables to the equation was analyzed, and the Sig. value was 0 lower than 0.05 . And because the regression coefficient is $0.750>0$, it is a positive correlation between the electronic commerce marketing mode and the macro environment factors. The significance test of the regression variables is shown in Table 6. Therefore, it is assumed that the H1 was founded, that is, the macro environment is better, the more likely that the retail business enterprise marketing model change.

Table 6. The Results of Regression Analysis of $\mathrm{H} 1$

\begin{tabular}{|c|c|c|c|c|c|}
\hline \multirow{2}{*}{ Model } & \multicolumn{2}{|c|}{$\begin{array}{c}\text { Unstandardized } \\
\text { Coefficients }\end{array}$} & $\begin{array}{c}\text { Standardized } \\
\text { Coefficients }\end{array}$ & \multirow{2}{*}{$\mathrm{t}$} & \multirow{2}{*}{ Sig. } \\
\cline { 2 - 4 } & $\mathrm{B}$ & Std. Error & Beta & & \\
\hline Constant & .903 & .228 & & 3.966 & .000 \\
\hline $\begin{array}{c}\text { Macro environment } \\
\text { factor }\end{array}$ & .750 & .065 & .759 & 11.523 & .000 \\
\hline
\end{tabular}

After the regression analysis, the regression variables were analyzed, and the significance of the regression equation was analyzed. The value of Sig. was 0. So the 
market competition factor had a significant effect on the electronic commerce marketing mode. Because the regression coefficient is $0.692>0$, it is a positive correlation between the electronic commerce marketing mode and the market competition factors. The analysis results are shown in Table 7. Therefore, it is assumed that the $\mathrm{H} 2$ is established, that is, the more intense the market competition, the more likely that the retail enterprises have to change the marketing mode.

Table 7. The Results of Regression Analysis of $\mathrm{H} 2$

\begin{tabular}{|c|c|c|c|c|c|}
\hline \multirow{2}{*}{ Model } & \multicolumn{2}{|c|}{$\begin{array}{c}\text { Unstandardized } \\
\text { Coefficients }\end{array}$} & $\begin{array}{c}\text { Standardized } \\
\text { Coefficients }\end{array}$ & \multirow{2}{*}{$\mathrm{t}$} & Sig. \\
\cline { 2 - 6 } & $\mathrm{B}$ & Std. Error & Beta & & \\
\hline Constant & 1.223 & .280 & & 4.366 & .000 \\
\hline $\begin{array}{c}\text { Market competition } \\
\text { factor }\end{array}$ & .692 & .085 & .636 & 8.168 & .000 \\
\hline
\end{tabular}

After regression analysis, the value of Sig. was $0,0.05$, so the enterprises own factors had a significant impact on the electronic commerce marketing model. And because the regression coefficient is $0.735>0$, it is a positive correlation between the electronic commerce marketing mode and the enterprise itself. The analysis results are shown in Table 8. So assume H3 was established. That is, the stronger the enterprise's own strength, the more likely the retail enterprise to change the marketing mode.

Table 8. The Results of Regression Analysis of H3

\begin{tabular}{|c|c|c|c|c|c|}
\hline \multirow[t]{2}{*}{ Model } & \multicolumn{2}{|c|}{$\begin{array}{l}\text { Unstandardized } \\
\text { Coefficients }\end{array}$} & \multirow{2}{*}{$\begin{array}{l}\text { Standardized } \\
\text { Coefficients } \\
\text { Beta }\end{array}$} & \multirow[t]{2}{*}{$\mathrm{t}$} & \multirow[t]{2}{*}{ Sig. } \\
\hline & B & Std. Error & & & \\
\hline Constant & .931 & .290 & & 3.210 & .002 \\
\hline Enterprise self factor & .735 & .083 & .668 & 8.897 & .000 \\
\hline
\end{tabular}

\section{Conclusion}

According to the results of empirical analysis, it can be seen that the macro environment factors, market competition factors and enterprise's own factors are positively related to the marketing mode of retail enterprises. These three factors promote the transformation of the traditional marketing model to the electronic business environment. E-commerce is not just limited to the online business, but also the application of information technology to the business activities of the enterprise management. The best mode of retail enterprises in e-commerce environment is the integration of e-commerce and traditional retail, which is based on the entity store to carry out network marketing, so that we can adapt to the shopping habits of consumers, make full use of the original resources, and can play computer information network technology advantages, improve the efficiency of enterprise marketing activities and market competitiveness.

The reasons for adopting the traditional retail mode and the electronic commerce retail integration mode are that: the change of ideas cannot be done overnight, the electronic commerce of China's retail industry can only take the road of gradual development. From the current situation, the electronic commerce retail defects can be used to make up for the traditional retail, if these two forms of combination, to play their own advantages, not only to accelerate the modernization process of the traditional retail industry, but also to provide full support for the development of e-commerce retail. Therefore, the best solution is to break through the predicament, which is to integrate e-commerce retail with the traditional retail model, to carry out the combination of the entity store as the basis of network marketing, e-commerce retail and traditional retail is a combination of two 
channels of retail. Compared with the pure e-commerce retail or traditional retail, the dual channel retail is more suitable for the retail business transformation.

\section{Acknowledgements}

The work of this paper is supported by The National Soft Science Research Program, Research on the Countermeasures of modern agricultural upgrading in Northeast China based on international science and technology cooperation, 2013-2014(2014GXS2D017).

\section{References}

[1] S. Djelassi, and I. Decoopman, "Customers' participation in product development through crowd sourcing: Issues and implications", Industrial Marketing Management, vol. 42, no.5, (2013), pp.683-692.

[2] H. Gebauer, M. Paiola, and B. Edvardsson, "A capability perspective on service business development in small and medium-sized suppliers", Scandinavian Journal of Management, vol. 28, no.4, (2012), pp. 321-339.

[3] E.H. Sinem, and Z. Kabaday1, "Innovation Orientation, Market Orientation and e-Loyalty: Evidence from Turkish e-Commerce Customers", Procedia - Social and Behavioral Sciences, vol. 99, (2013), pp. 509-516.

[4] I. Janita, W. Chong, "Barriers of B2B e-Business Adoption in Indonesian SMEs: A Literature Analysis ",Procedia Computer Science, vol. 17, (2013), pp. 571-578.

[5] M. Savrul, "The Potential of E-commerce for SMEs in a Globalizing Business Environment", Procedia Social and Behavioral Sciences, Vol.150, (2014), pp.35-45.

[6] S. Deniss, "Impact of e-environment on SMEs Business Development",Procedia - Social and Behavioral Sciences, vol.156, (2014), pp. 409-413.

[7] M. Shoki, L. Yun, and N. Zakuan, "Examining Dimensions of Electronic Service Quality for Internet Banking Services", Procedia - Social and Behavioral Sciences, vol.65, (2012), pp.854-859.

[8] A.D. Zaridis, and T. Dimosthenis, "Entrepreneurship and SME's Organizational Structure. Elements of a Successful Business", Procedia - Social and Behavioral Sciences, vol.148, (2014), pp. 463-467.

[9] S. Manjit, and V. Kristine, "Social Commerce: A Contingency Framework for Assessing Marketing Potential", Journal of Interactive Marketing, vol. 27, (2013), pp. 311-323.

[10] K. Grant and D. Edgar, "Risky business: Perceptions of e-business risk by UK small and medium sized enterprises (SMEs)," "International Journal of Information Management", vol. 34, no.2, (2014), pp. 99-122. 
International Journal of Security and Its Applications

Vol.9, No.11 (2015) 